\title{
Tres Poetisas Argentinas
}

\author{
ALFONSINA STORNI
}

$\mathbf{E}^{L}$ alma del verso es y será el ritmo. El verso sin ritmo es como una sombra sin cuerpo, como un vaso sin contenido. E1 ritmo del verso lo establece una ley científica; aquella que según Tyndal y Spencer "rige todos los movimientos y cambia la agitación en ondulación regular". En última instancia podrá prescindirse de la rima, del atavío, pero jamás del ritmo, traductor de un estado en que las palabras interpretan la música de las ideas.

Es debido, en parte, a la nobleza o novedad del ritmo, que muchos poetas perduran sobre el tráfago y la confusión de tendencias que se disputan el predominio de la moda. Entre ellos - dado que la poesía no reconoce sexo- cabe destacar en primera línea a Alfonsina Storni. En la lírica americana esta mujer es la de la imaginación más densa y lenguaje más rico. Su modalidad es absolutamente subjetiva, espiritualizada.

El erotismo, llevado a la máxima profundidad en la Agustini y a la suprema gracia en Juana de Ibarbourou, cobra alcurnia intelectual en Alfonsina. Esta rige sus instintos como un piloto la nave. Su voz ha llegado a una transparencia tal, que pudiéramos decir no conserva rastros de lo inconsciente. Sin turbias complicaciones de la líbido, su poesía disciplinada, sujeta a control, tiene la virtud de conservar impoluta la gracia estética, bajo la acción siempre latente de una cultura intelectual muy extensa.

Desde su primer libro, la línea directriz de Alfonsina Storni se mantiene en ascenso. De La inquietud del rosal a Ocre, observamos cómo se aclaran sus motivos, tornándose cada vez más interiores, más trascendentes, más restringidos al diálogo psicológico. Un diá- 
logo del alma con el mundo, de la inteligencia con las pasiones, de la criatura con la naturaleza. La idea se trasmite en su verso como por nervio sano y poderoso.

Su poesía no es más que condensación de estados de conciencia, un flujo y reflujo de la marea angustiosa y atormentadora de su pensamiento. Marea en la que por modo luminoso flotan sus cualidades: profundidad, armonía, elevación. Profundidad del pensamiento que ahonda en la vida, inquietado por su misma intensidad; armonía entre el concepto y el ritmo; elevación de lo cotidiano a lo trascendente, de la existencia diaria a los grandes problemas.

Cerebro y corazón se hacen verbo vibrante en labios de esta poetisa. Verbo que en La inquietud del rosal se halla tocado de gracia; en El dulce daño, de una tamizada voluptuosidad y un dolor atemperado; en Irremediablemente, de un ansia interrogante y tn religioso fatalismo; en Languidez, de un deseo de aquietar el cerebro doliente, de no sentirse marcada por la duda, de no saberse acicateada por la fatiga de buscar. En Ocre - libro de madurez- - todos estos aspectos se fusionan, se ensanchan, se saturan de lo más íntimo de la sensibilidad femenina, alcanzando tn bien regido estilo y una forma perfecta.

Analítica, disciplinada, estudiosa, Alfonsina Storni -a través de sus ocho libros - muestra una cultura intelectual compleja, como pocas mujeres la tienen en América. No obstante, su arte se mantiene libre del influjo desvirtuador del intelectualismo profesoral, que tantos estragos causa en los climas librescos. Digo esto porque Alfonsina Storni, dada su profesión de bibliotecaria, podría caer con facilidad en tales vicios, máxime si se considera el predominio que en ella ejerce la mente sobre sus otras actividades. Pero no ha sido así. Su intelectualismo se nota única y exclusivamente en la arquitectura del verso y en la riqueza de metáforas de que hace gala en sus obras, sucediéndose una tras otra, en singular y renovada tensión.

Su mecánica poética, aunque conserva en buena parte la rima, brinda la primacía a la asonancia y al versolibrismo. El ritmo es lo que adapta a la idea, no la idea al ritmo. En algunos de sus temas, vagos y candorosos - aunque se muestra arbitraria, de una arbitrariedad mental - no cae nunca en el prosaísmo ni en la incoherencia. La manera sintética y esquemática que usa para expresar la emoción y los más tenues movimientos del espíritu, es lo que la lleva a descomponer el verso, no el afán de novedad. Alfonsina Storni, en cuatro 
rasgos, con parcas descripciones e imágenes justas, al evocarnos su vida interior, nos pone frente a la eterna intimidad femenina, y con un ritmo simple y un detalle en apariencia trivial, tiene la virtud de remover nuestras ideas y los ensueños adormecidos en el alma.

Pero esto no le basta. Su hambre de captación psíquica quiere superar lo literario. Es entonces cuando aparecen sus Poemas de amor, simples frases líricas, de las que surgen los estados de tensión erótica, maduros ya para la vida. Hay en las páginas de este pequeño volumen una maestría que descansa en lo sencillo de la expresión y lo robusto del sentimiento. Su sensualidad altanera se traduce en un grande y nuevo entusiasmo. Para ofrecerse al amado, no vacila en proyectar su alma fuera de sí, y para elogiar su orgullo reflejado en el ser a quien se entrega, halla comparaciones y palabras de rara justeza. De este amor carnal, en el que no se sabe si el alma se transporta a lo físico, o si lo físico asume categoría de alma, extrae Alfonsina Storni la esencia de que está impregnada su prosa poemática, que "apenas si se atreve a ser una de tantas lágrimas caidas de los ojos humanos”. Es una esencia fuerte, inquietante, urgida. En los momentos de soledad, la mujer clama con voz desgarrada y frenética: pide perennidad al momento en que no hace más que morir, quiere que se perpetúe en las frases que le brotan - como la hoja tierna al tallo nuevo- la angustia de la espera, el temor a destruir el recuerdo, el latir apresurado y el desmayar intenso del orgasmo.

De esta tensión de la madurez psico-física, sale Alfonsina para incursionar en el teatro. Con El amo del mundo se penetra en el campo del intelectualismo vigilante, hecho a descargarse en el debate y a irse ahondando en la idea. Como en el teatro de Bernard Shaw, en el de Alfonsina Storni el diálogo lo es todo. En esta obra, como posteriormente en sus Dos farsas pirotécnicas, la acción está reducida a un proceso de ideas. En plan polémico, su beligerancia intelectual es una constante afirmación del ser humano. Toma algunos personajes de la tragedia clásica y los conduce a la vida, para que la interpreten obedeciendo a determinado fin.

La dramática conversación que es El amo del mundo, posee cuatro méritos modernísimos: plasticidad, arrebato, trasposición de lo antiguo a lo moderno y sostenida polémica en torno a almas contradictorias, que no son más que imágenes subconscientes de la autora, bregando por descubrir la significación del pensamiento en toda su pureza. 
En Cimbelina en 1900 y pico, al igual que en Polixena y la cocinerita -sus dos farsas pirotécnicas--, la palabra alusiva y alquitaradísima, consigue su más aguda presión. Un mundo destilado de la literatura: el propio mundo de Eurípides y Shakespeare, se hace evidente en almas actuales, sutiles y retorcidas, que ya no dialogan a la manera antigua, sino que al ir adquiriendo nuevos atributos se han emancipado de la circunstancia que las originara.

Lo que pasa con Alfonsina Storni es que siente la vida en término intelectual y la piensa en término de pasión. Cuando María Elena, en Cimbelina en 1900 y pico exclama: "en una farsa toda verdad realizada es una verdad posible. ¿Sabes tú lo que yo soy capaz de hacer con la imaginación?", delata la índole del pensamiento de Alfonsina. Un pensamiento que busca dilucidar las dos caras del mundo: la lúcida y la subconsciente. En la trasposición de épocas y caracteres lo que persigue es el punto en que cambia el valor del esfuerzo, y se gana por la acción el aclaramiento rápido de las ideas. Todo en A1fonsina Storni tiende a la contradicción. $Y$ atinque al principio desconcierte, al fin y a la postre se cae en cuenta de que su propósito es la demostración de que la humanidad ha crecido psiquicamente.

Riqueza interior, crecimiento y un ir volcándose en la vida, es lo que evidencia Mundo de siete pozos, el libro que contiene las más extrañas, tensas e inaprehensibles páginas de Alfonsina Storni. Este es ya un lirismo de angustiosa expresividad humana, que se ha ido vaciando en forma no menos expresiva y novísima. Si en los versos anteriores daba impresión de intensidad y lucidez, en el último libro estas cualidades se depuran, crecen y ahondan en el limo psíquicobiológico. A ellas se agrega un dramatismo cósmico, integrador, y un entusiasmo por descubrir las correspondencias intuitivas del mundo, que la poetisa parece haber mamado de los metafísicos orientales. También asume una deliberada novedad de imágenes. En "Voluntad" dice, por ejemplo:

$$
\begin{aligned}
& \text { Mariposa ebria, } \\
& \text { la tarde } \\
& \text { giraba sobre nuestras cabezas, }
\end{aligned}
$$

y para expresar su acongojamiento cotidiano - veneno del espírituelabora metáforas de singular interés:

Te ataré

a los puños 
como una llama,

dolor de servir

a cosas estultas.

("Voz.")

Su espíritu alerta es como levadura que levanta la masa de la palabra instigadora. Hay en el donaire frecuente de los vocablos de Alfonsina Storni, la constatación angustiada de la vigilia y el sueño, y el tormento de saber que lo perdido retorna alguna vez en la marea subconsciente. Ese oscuro deliquio lo traduce en voces por las que circula una corriente de amor:

Mas no era boca. A musgo macerado

en los soles de Dios, se parecía.

Pájaro de aire, reposó la boca

sobre la boca mía anochecida.

("Regreso en sueños.")

No contenta con traducir objetivamente el mundo subterráneo, toma lo objetivo, suéltalo de amarras, y lo conduce hasta dotarle de nueva categoría en el plano de la subjetividad. Todas las inquietudes del corazón y las alarmas de la carne, lo que en el mar o en la tierra hiere su memoria, hasta lo que nadie osa confesar, Alfonsina Storni lo recoge en la forma lírica. Uno de los criterios de la mujer actual: el goce sin consecuencia, la deliberada no concepción, desprendida ya de complejos y represiones, lo integra en un soneto sumamente bello:

Cada rítmica luna que pasa soy llamada por los números graves de Dios a dar mi vida en otra vida: mezcla de tinta azul teñida;

la misma extraña mezcla con que he sido amasada.

Y a través de mi carne miserable y cansada

filtro un cálido viento de tierra prometida, y bebe, dulce aroma, mi nariz dilatada a la selva exultante y a la rama nutrida.

Un engañoso canto de sirenas me cantas, naturaleza astuta. Me atraes y me encantas para cargarme luego de alguna humana fruta.

Engaño por engaño: mi belleza se esquiva al llamado solemne; y de esta fiebre viva, algún amor estéril y de paso disfruta. 
Estos versos de tan punzante y complicada delicadeza, traducen parte importantísima de la filosofía sexual de la nueva generación. La realidad física, gracias al valor patético que le confiere la escritora, se ha elevado a la categoría de realidad artística.

Con esta "Canción de la mujer astuta" y con las extrañas y desoladas "Razones y paisajes de amor", avanza Alfonsina Storni hacia una poesía infrecuente, elevada casi de modo sustantivo sobre ideas. En Mascarilla y trébol y en sus poesías no conocidas, se dosifica en mayor medida la cualidad intelectiva que supera en mucho a la simple expresión de los afectos. Rompiendo de modo absoluto con sus modalidades anteriores, y prolongando, en un afán depurador, el ámbito de Mundo de siete pozos, Alfonsina se muestra a la manera de un prisma en el que se subordina el mundo a la preocupación metafísica, a la inquietud filosófica, a la introspección de los hechos inconscientes, hasta alcanzar estados en los que se diría que su lucidez se va tornando sonámbula.

La definición más evidente de esta novísima arquitectura poética de Alfonsina Storni, es su carácter simbólico. Se perfila desde el título del libro, en el que la mascarilla de la muerte y el trébol de un destino ilimitado, expresan el drama de la mujer poeta y del tiempo en que se debate. El mar es un motivo proteico en el que la escritora se sumerge en busca de las leyes universales que hacen que los cuerpos retornen al limo. Pero, subyugada por las fuerzas vitales del amor y de la belleza, y aun sabiendo que se encuentra ciega frente a la vida, recurre al verso en sofrenadas alegorías, en el goce fecundo de que lo poético resulte vencedor de los años.

De preferencia cultiva un soneto sin asonancias ni rimas, de una música interiorizada que opera a base de cristalizaciones y de la que se va levantando un mundo angustiado que es por excelencia el mundo de los altos mitos. Con apretados haces de metáforas, muchas de ellas de una desgarradora novedad, la mujer poeta va penetrando hasta las profundidades del trasmundo para entregarse a un coloquio entre las fuerzas oscuras y el difícil pensamiento.

Como una obsesión le vuelve el tema del hijo y el de la esterilidad, que se levantan de su conciencia por la magia dolorosa de la imaginación. He aquí la nueva forma en que se vierte su ansiedad materna: 
Una frase brutal te corta el paso $y$ aun risas y no sabes si el que empuja te arrolla siempre o Angel se despliega.

En ésta y en otras poesías, la mujer aparece como reflexionando clespués de un trance cósmico en el que la desesperación le hubiera mostrado las cosas en un perpetuo desgarrarse y en continuo desasirse.

Las ultimas expresiones de Alfonsina Storni, por lo mucho que se han apartado de una poesía sobresaturada de esencias románticas y por lo que mueven hacia una posición crítica, están condenadas a no obtener la preferencia de la mayoría. Lo que en ellas aparece es la maduración en el pensamiento y la solidez en el estilo emocional.

Cristalizaciones perfectas de una energía dramática, sus poemas se concretan en conceptos rotundos y en intelecciones controladas. Frente a una lágrima, una oreja, un diente, como frente a las sugestiones del Río de la Plata, de una cuna vacía o del cielo abierto, lo que la poetisa capta es un eco de las fuerzas cósmicas, en las que desea trasfundirse, a base de experiencias personales y avidez en torno al mero conocimiento sensible. Tiene esta poesía un tono ascético, un interrogar constante y una desolación que se mantiene en el afán filosófico, y en ella, el ajuste entre el fondo y la forma es de una perfección tan difícil, que se diría ha sido alcanzada a fuerza de introversión.

Lo que la distingue es su aristocracia mental, conducida hacia dimensiones simbólicas, y una forma culterana que hace de Mascarilla y trébol una obra con destino a las minorías.

Así la amó y así le fué otorgando su preferencia esta mujer atormentada, que después del terrible tránsito donde la duda resplandece por años y años, se fué interiorizando cada vez más hasta desajustarse de manera casi absoluta con el mundo. Fueron tal desajuste y tal disconformidad con las cosas y con su alma, las que impulsaron a Alfonsina Storni hacia la muerte voluntaria, que encontró entre las olas de Mar del Plata, en 25 de octubre de 1938.

La suya es la tragedia de un espíritu que era demasiado luminoso para un mundo en tinieblas, y para encontrarle salida, quiso devolver al agua, en la que gestan los mitos, todo su cargamento de tensiones, y la contradicción de un ser que fué el más íntegro de cuantos en América han padecido y han amado. 


\section{ELVIRA DE ALVEAR}

Elvira de Alvear es poetisa de escritura nueva. Leerla supone cierta preparación y un estado de ánimo afín. Su sensibilidad procede por iluminación. Su poesía no está regida por el claro dominio de la inteligencia, sino que se ilumina a chispazos de intuición. Es poesía de calidad puramente adivinatoria. De adivinación elaborada, lenta, que clarifica las circunstancias del subconsciente.

La poesía de Elvira de Alvear aporta a la lírica femenina los perfiles del suprarrealismo. En momentos en que se va cayendo en la uniformidad, su voz sobria sustituye las raíces directas de la aportación sensual y la armonía ya clásica del modernismo, por otro sistema de equilibrio y de mecánica interiores, en los que la disgregación emotiva está finamente ligada a la aventura y las inquietudes del mundo externo.

E1 de Elvira de Alvear es un sentido que carece de contornos. Su esfuerzo lo concentra más en el contenido que en la expresión. Su mundo poético está tomado casi todo de las alarmas del espíritu frente a las circunstancias del paisaje.

De este modo le da forma a una poesía menor, sostenida por la prolijidad durmiente; una poesía que no es de claridad perfectamente inteligible, sino de claridad deliberada, que hay que saber comprenderla. No es la suya la honda meditación ni la patética confidencia; es ei germen de lo que está y se soslaya, la arquitectura de matices finos y delicados, el léxico sonámbulo que busca a la naturaleza a través del subconsciente.

Escribir, para esta mujer, es captación del ser en sí y en las circunstancias en torno. La emoción, en ella, dormita en las antesalas del vivir, mas es vecindad entrañable y gozosa de todo el mundo pensante. La subconsciencia no hace sino reverdecer el fervor de que viene portadora. La subconsciencia le sirve para reconcentrarse en lo vivido, allegando la emoción a los grandes laboratorios de la alquimia del alma.

Entonces, recobrando caminos de existencia insospechada, su dolor se torna sereno, dadivosa su quietud y opulento su reposo. La poetisa empieza a ser lo que es. En lugar de la abstracción sentimental, del gozo de la correspondencia amorosa, de la angustia del amor sin respuesta, los poemas de Elvira de Alvear persiguen las apasionadas divagaciones de la emoción, íntimamente ligadas al paisaje entre- 
visto y a los recuerdos, que asoman un momento para volver a la oscuridad anímica.

Este sistema de estructuración poética choca a primera vista, y se presta a que se le tome por oscuro y laberíntico. Ya no sucede igual cuando se le confronta con los pormenores cotidianos. Entonces se cae en cuenta de que la interferencia del paisaje y el recuerdo es fenómeno que aprovecha todos los huecos del vivir.

Una rinconada de parque bañada por la luna está unida al sabor de un beso; el angustioso alarido de las locomotoras se entremezcla a una despedida; una rosa marchita en el jarrón de porcelana se halla enraizada a la ruptura de una cita. De pequeños pormenores, de circunstancias alusivas, está abarrotada la subsconciencia, y en actitud sorpresiva, en el momento más insospechado, surgen a la superficie adquiriendo vivencia momentánea.

Estos momentos son los que Elvira de Alvear aprovecha para la elaboración de su poesía. Poesía pormenorizada que opera a base de circunstancias; si se la moteja de oscura es por una confusión de conceptos. La poetisa argentina no es oscura, sino difícil. No es que sus emociones adolezcan de falta de cristalización ni que su pensamiento se mantenga en una atmósfera tenebrosa. Al contrario, su emoción está madura y es preciso su pensamiento, pero su figuración poética es complicada, y su acto ideatorio concuerda con la alusión, el concepto, el matiz, surgiendo en forma veloz, incontrolable $y$ espontánea.

Otro de los caracteres comunes a su sensibilidad, es que trabaja poco a base de esquematizaciones, para seguir una pronunciada línea de extensión. Sus mejores poemas - "Descanso", "Vencida", "Obsesión", "Bordados"- son de largo y mantenido aliento. A pesar de su extensión, ni se aminora ni decae su intensidad. Lo intenso en esta poesía se alimenta de saturaciones contrarias.

La ardiente persecución de los recuerdos, las frases líricas truncas, como idas, y la unidad emocional, gritan un sentido alerta y dinámico de la finura y atención del ajuste verbal, por la analogía y oposición de sus palabras, y por el conocimiento que manifiesta de las contradicciones del espíritu.

Lo grato está en la armonía difícil, en el punto en que se unen 1o emotivo y lo abstracto, en el contraste en que la palabra adquiere nuevo contenido. Así, en estos versos que destaco: 
La pena sometida a duro trance.

E1 miedo poderoso de perderte para siempre, a través de nuestras vidas del origen de creación no se lance. Autoras destempladas de la muerte hacia atrás, rotas, desaparecidas entre las cosas que nos son ajenas.

Hay armonía, vale decir, la concordancia entre el sentimiento de la pena, el temor a que el amado se aleje y no retorne, y la medrosidad ante el presentimiento de la muerte.

Hay la relación emotiva del "duro trance" y "el miedo poderoso" y la relación abstracta de lo que es ajeno. $Y$ hay el contraste entre el sentido de lo perdido, que origina el estado emotivo, y el acto de lanzar la destemplanza hacia las cosas que por ser extrañas han dejado de interesar.

Elvira de Alvear obtiene una novedad de imágenes sorprendentes. En el principio del poema "Descanso", dice:

$$
\begin{aligned}
& \text { Llevo como una memotia mi pena, } \\
& \text { que se quisiera olvidar y no puedo, } \\
& \text { que la desgarra a uno de dolor } \\
& \text { como implorando una palabra plena } \\
& \text { de dulzura, llama que desenreda } \\
& \text { estos días quietos, con su fulgor. }
\end{aligned}
$$

Hay en todos los poemas de su libro Reposo algunos detalles de lirismo que merecen dilatada atención. Elvira de Alvear renteva la imagen de las primeras horas del amanecer, notando que:

Derramó la leche el alba sobre el gran jarrón del parque débil principio insinuado en la hermosura para inconstante.

Los motivos que le dan el calor y la soledad son casi siempre aprovechados bellamente por esta poetisa, a la que podría llamarse exégeta de la inquietud eterna en el reposo físico.

Todo vuelve a ella en una constante transfusión de recuerdos. Ya se la ve en "Obsesión" aludir con doliente persistencia a las circunstancias infantiles:

Es una memoria que vuelve desde la infancia insinuando ternura... 
De esta memoria casi táctil, que "es una construcción perfecta y acabada", extrae Elvira de Alvear el aroma de que están empapados sus poemas. Es un aroma fino, delicado, perturbador, que parece recién infiltrado en la poesía argentina.

En las horas dolientes, la poetisa sabe expresarse con voz transida: pide la permanencia en in mismo sueño de bondad que siente; desea que el llanto no atenúe su sed de ideal; y quiere ser más grande, de pureza mayor, y cuando intuye sucesos nefastos, ansía que el amante y ella estén: presintiendo las desgracias
unidos en una lágrima.

De esta dulce tensión está llena cași toda su poesía. Hay en la angustia frecuente de que está impregnado su lirismo, el tormento de verse conducir sin ruta fija por el destino y de que el alma se le haya bifurcado en un deseo y una añoranza incolmable:

en una ciudad densa, conformando mi sueño donde vivos recuerdos que nadie ha imaginado hace ya muchos años, como dados risueños mi suerte cae de golpe, de un lado y otro lado.

Otras veces la mujer siente brotar a caño abierto el ímpetu maternal, quiere ser guía y protectora del amante y vuelca así todo stu amor:

De la muerte guardarte, impedir tus viajes y ausencia que me desangran, protegerte del mal y de los demás, por mi causa hacer que te pertenezcas, ser por fin lo que pudiste haber sido.

Pero el tono apacible no es óbice en encubrir la actitud doliente que la domina. Quiere ser una con su amor hasta el agotamiento, hasta recobrarse, no en apariencia sino en el interior, el cariño que se les iba extraviando. El balbuceo, el continuo acongojarse y la ternura entrañable rigen sus palabras por momentos inconexas; sus voces que no llegan a acordarse y por las cuales se adivina la presencia del amor y la sombra clarificada de la tristeza. En un casi delirio, operando por las rutas inconexas de lo subconsciente, se pregunta: 


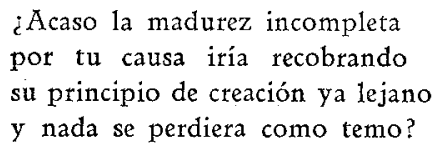

$Y$ más adelante, con una expresión simple y clara, logra connotaciones emotivas y abstractas, como cuando dice:

y cada instante el dolor más hundido

en la angustia de esperar una cifta.

Con estas notas de inexorable tristeza, con este angustiarse de continuo por lo que cambia y lo que permanece, con este traducir el mundo interior para relacionarlo con el mundo externo, Elvira de Alvear ensaya la elaboración de una estructura posible.

Lo autonómico de sus versos, desiguales en sus partes, y hasta con exceso atomizados, se compensa de sobra gracias a la plenitud que por esos medios obtiene en el conjunto.

Los poemas de esta mujer, de una inconexión aparente, son de íntima unidad cerrada. Su poesía sugestiona $y$ atrae a quienes sienten curiosidad por los problemas del alma y por la libre elaboración del fenómeno estético.

Elvira de Alvear es poetisa de plenitudes artísticas entrañables, que, cuando el arte se mueve dentro de una órbita de temas sexuales y de técnica, siente la necesidad de remover por dentro a la poesía, de intentar renovaciones sonámbulas, de saltar del realismo de la mujer que vigila a ese otro realismo de la mujer que sueña, y que en el sueño continúa viviendo realidades vistas o pensadas.

Por eso descuida deliberadamente la expresión, para ejercer vigilancia sobre el concepto, integrado por el dualismo de la vigilia y el sueño. De ahí esa trabazón íntima, esa continua interferencia, ese pasar sin transiciones del plano objetivo a las rutas subjetivas.

Si, además, Elvira de Alvear ha elevado las categorías de lo imaginativo a un tono de patetismo interno, si crea nuevas connotaciones alusivas y de matiz, si hace más sensibles los hechos psicológicos en las cifras de lo objetivo, merecerá siempre una cuidadosa atención y un estudio amoroso de los artistas. 


\section{NORAH LANGE}

Norah, mujer nobilísima y con talento extraordinario, es argentina, aunque desconcierte su apellido de fino entronque noruego: Lange. Nació en Villa Mazzini y pasó los mejores años de su infancia al pie de la cordillera. Mendoza la cobijó entre las sombras de sus árboles y su vivir fué como la clara melodía de un acordeón.

En arte, Norah Lange se ubica entre el mocerío de 1922. Los viejos árboles de la calle Granada la encontraron tejiendo sus primeros versos. Escribe porque una fuerza interior la obliga a ello. Nunca la preocupan las fórmulas y si versifica es a pesar suyo. Le place decir las cosas con sencillez y sin darle importancia a las arbitrariedades. El atuendo arbitrario de su poética es la resultante de influencias comunes a su época, de gustos y modos característicos de la promoción en que actúa. Lo homogéneo y frecuente en las ideas es lo que labora la fisonomía literaria.

Abrir un libro de Norah Lange, ya sean los circunscritos al verso - La calle de la tarde (1924), Los días y las noches (1926), El rumbo de la rosa (1930) - o los vaciados en períodos en que la prosa canta -Voz de la vida (1927), Cuarenta y cinco dias y treinta marineros (1933) y Cuadernos de infancia (1937) -, es encontrarse con un temperamento anárquico, de profunda insurgencia social, que, a semejanza de Gabriela Mistral, gusta de hacerle guiños satíricos a la cultura universitaria. Usar de la prosa o del verso, es para Norah el arte de interpretarse a sí misma. Poesía de la más alta calidad es lo que realiza en uno y otro género. Su poesía es una búsqueda constante de lo que se puede perder y de lo que se desea ganar. Lo que sostiene, empuja y da fuerza a sus perfiles literarios, es ir afirmando la vida.

$\mathrm{Su}$ actitud especial provocada por un disconformismo interno, conduce a Norah a sostener acrecida pugna con todo convencionalismo. Sus actitudes, erigidas en Babel de rebeliones; sus escenas, improvisadas con el objeto de remover el estatismo urbano; sus escándalos artísticos, finamente premeditados y que estallan como obuses en la estandarización conformista, poseen lineamientos comunes. El origen de tanto hecho que escapa al rasero cotidiano, hay que buscarlo en su intranquilidad. No puede permanecer tranquila por la sencilla razón de que siente agudamente la queja de los oprimidos y se atormenta 
buscando medios para remediarla. Poesía o prosa, los construye subjetivamente.

Su lenguaje delicado, recoge y tamiza los momentos de más difícil exteriorización. Norah es una voz que por no vaciarse a gritos ha decidido cantar a la sordina. Esto no obsta para que en el fondo de su espiritu sienta - como dice Omar Viñole- el peso formidable de los "fantasmas codificados", y luche por emanciparse definitivamente de su influencia.

¿Norah Lange es sobrerrealista? La etiqueta no vale sino para el fichero de los eruditoš. Es una mujer que canta. Sus libros pueden encasillarse dentro de cualquier escuela actual, porque su rango tiene algo de todas y las sobrepasa en espontaneidad. No es la vestidura o el adorno lo que importa en Norah, sino la esencia que guardan y el sentido que mueven. Su afirmación es vital, no conceptista, y lo que en ella sobrenada es el soplo ardoroso de humanidad y de lirismo dramático.

Sus libros cambiarán del poema en verso a la prosa poemática, de las exploraciones internas a los cuentos de marineros, pero en el fondo, lo que debaten, es el problema angustioso de vivir. Lo que en su arte interesa son las realizaciones y el conocimiento humano que generan. El vivir intuitivo es en ella de una densidad tan grande que se diría limpio de todo lo que significa paramento. Los impulsos de la emoción pura discurren en sus obras como un aleteo de palomas que van por los caminos de la metáfora.

Si en medio de su fecundidad la hora presente posee algo de estéril, su esterilidad depende de que no se crean formas esenciales de vida, sino que place tan sólo discurrir en su dintorno. Esto no acontece con Norah, quien, con las imágenes que acuña, simboliza lo más profundo de su dominio interior. Escucha el llamado de la vida y quiere interpretarlo. Todo su sentido está en el esfuerzo de la imagen hacia dentro, hacia el arroyo emotivo que, atn soterrado, no deja de correr un instante en la tierra de todos los días.

Cuando crea, lo hace con absoluto desinterés, y en la ideación verbal depura sus facultades intuitivas, y obtiene realizaciones vitales sin precedente. La poesía de Norah capta esa fuerza de hallazgo y dádiva, de imagen y sentido, de esperanza y destino, que en su esencia informa las conquistas más importantes de la literatura actual.

Lo elaborado de sus metáforas remueve y profundiza en el mundo interno; la suya es la metáfora-polo de la energía intuicio- 
nal; bajo su lenguaje que canta a sotto zoce operan formas retrospectivas, haciendo presentir ímpetus irrefrenables, que la obligan a pasar por todos los estados gestatorios de la plenitud maduradora.

La metáfora es el material de que se sirve para la estructura de su poesia. Millonaria en calidades, con una sostenida nota de individualismo, posee Norah una clara languidez, un ahondamiento de esperas, una dicha tímida y una gozosa pesadumbre. Con esto quiero significar que aun cuando Norah Lange cultiva el sobrerrealismo, no deshumaniza la poesía.

Eso la diferencia de sus congéneres, de quienes tratan por todos los medios de ir fabricando poemas en esqueleto, de quienes pretenden una poesía exilada de personajes, caracteres, ideas y sentimientos. Norah no padece de tales limitaciones que, a fin de cueatas, no significan otra cosa que una enfermedad de la fantasía. Por el contrario, esta argentina de ascendencia noruega posee la virtud de que sus imaginaciones, a fuerza de ser reales, acaban por parecernos fantásticas.

El descubrimiento de Norah se debe a Jorge Luis Borges - poligloto, ensayista, poeta-, que ha oficiado, para ella, de introductor y de maestro. Por eso tienen algo de común sus fisonomías líricas. Algo de común en la forma, no en el fondo. Norah es demasiado femenina para que se parezca a un hombre, aunque ambos poseen elementos profundos, elementos enmarcados en la categoría perfiladora de una generación; en este caso, la generación argentina de 1922 a 1927.

La poesía y los cuentos de Norah poseen un valor pimentoso, una gracia amarga y un tono elevado en el que los aciertos de ex. presión y los equilibrios formales se originan en la presencia constante del hechizo vital.

Todos sus libros brotan de sensaciones internas y personales y tienden a convertirse en representaciones de su esperanza, de su felicidad o de su angustia. De La calle de la tarde a Cuadernos de infancia se presiente, cada vez más afinada, la exploración autobiográfica. Claro que esas exploraciones se nos presentan habitadas por el caudal emotivo de quien desea aferrarse, ahincadamente, a los recuerdos. De recordaciones infantiles están hechos precisamente sus Cuadernos, en los que se transporta al "tiempo perdido" para vivir, pálida y triste, junto a "la ternura que recorrió su infancia". 
Norah Lange se ha ido despojando de todo artificio, y el esfuerzo de pulir el idioma hasta sacarle brillo apenas se nota en esta prosa, en la que, cuerda a cuerda, van danzando los días de cinco muchachas con las cabelleras agitadas por el viento de la Cordillera. Descubre el medio familiar, con tan altísima ternura y ritmo tan conmovedor y melancólico, que a ratos se piensa, no en la autobiografía de una "muchacha", sino en los poemas de Tagore.

La gran prosista que se pone en pie en los Cuadernos de infancia, ha recibido de Buenos Aires un doble galardón. En 1937 le fué otorgado el Premio Municipal y en 1939 el Tercer Premio Nacional, con lo que Norah se ha destacado plenamente entre el conjunto de escritores argentinos.

Cuadernos de infancia es libro que va solo, brotando de los redaños del alma como un perfume de las profundidades de un bosque. Estampas de índole poemática, que principian y se cierran en sí, como eslabones de una cadena de diez años, los capítulos de Cuadernos de infancia son para leerlos en voz queda y para recordarlos a la hora en que el crepúsculo nos pone melancólicos. Pocas infancias se nos han otorgado con tanta plenitud, sin ocultamientos de ninguna índole, como ésta en que Norah Lange nos lleva de las manos desde los árboles de Mendoza hasta los árboles de la calle Granada, en la que entrevemos la ruina de la casa y el hombre decente, soslayada con elegancia y que en ningún momento da origen a actitudes de rencor.

Cuando más, lo que entrevemos en Norah es el rodar de una lágrima sobre unos labios que sonríen. Cuanto evoca ha sido tocado por la varilla del pudor; un pudor de los sentimientos en el que no hay sitio para las cosas desagradables. Cuando cerramos Cuadernos de infancia, lo que más alto flota sobre nuestra conciencia son las estampas de la muerte del padre y la muerte de Estercita, la hermana menor, a cuya vera el recuerdo se le va quedando inmóvil y le brota como una añoranza asordinada y deliciosa. La realidad de su vida ha obrado sobre Norah a la manera de tábano socrático. Superándose a sí misma, ha hecho de su vida infantil un manantial perenne de belleza. $\mathrm{Su}$ voz resuena aterciopelada y cuando evoca goza como mariposa ebria en torno a la llama dichosa de su infancia.

La sencillez formal, de tan difícil pureza, a que asciende Norah, es la resultante de una larga paciencia y de una silenciosa disciplina. Trabajando en la cantera de sí misma, ofrece las sensaciones de la 
vida cotidiana y a puñados de recuerdos se va construyendo el infrecuente bien de un lenguaje rico y un estilo claro.

Después de la segunda edición de Cuadernos de infancia, Norah Lange anuncia un volumen de Discursos y correspondencias, en el que la veremos con los ojos azules y el cabello de azafrán, juntando sus ternuras como quien junta espigas de ideas.

Muchas cosas tiene que decir, y pudiendo hacerlo en siete u ocho idiomas, el único que emplea es el de los recuerdos, de que se va despojando como si desnudara sus dedos de sortijas. Así queda, frente a la vida, con las trenzas en arco, entre los labios la boquilla esbelta que remata en el cigarrillo perfumado, yendo y viniendo las manos sobre el desplegar de un acordeón, en la "espera dichosa del libro que saldrá".

Julieta Carrera, La Habana. 
